Forthcoming (2015), Journal of Cultural Economy's Special Issue, Prototyping cultures: art, science and politics in beta, ed. Alberto Corsín Jiménez

\title{
The interior design of (free) knowledge
}

\author{
Alberto Corsín Jiménez, Adolfo Estalella and Zoohaus
}

\begin{abstract}
What would a 'free knowledge bank' look like if it were to be designed as an architectural object? The challenge was posed by El Ranchito, a curatorial project based at Madrid's contemporary art centre, Matadero, to the art and architectural collective Zoohaus in 2011. The project aimed to turn into a 3-D model (hereafter known as the Offfficina) a variety of architectural 'collective intelligences' (based on do-it-yourself, retrofitted, community-driven architectural designs and adaptations) that Zoohaus had long been collecting and documenting from locations the world over. This essay tells the story of the making and travails of the Offfficina. It describes the work that Zoohaus has been carrying out in documenting constructive techniques worldwide: their use of diagrams, photographs, videos, or digital social media in experimenting with, or improvising new models and forms of architectural representation. Further, it describes the challenges faced in turning such 'models' into 'prototypes': when the experimental form must remain openly recursive to its own re/presentational sources. The paper ends by describing the most radical of such recursive transformations, where the Offfficina was turned into an 'ambient' or atmospheric object, and in the process reimagined (free) knowledge as dimensional piece of interior design.
\end{abstract}

Perhaps the most famous dinosaur in the history of science is the model of the Iguanodon monster inside whose mould Benjamin Waterhouse hosted a New Year's Eve dinner party at the Crystal Palace in 1853. James Secord has recently commented on the role that the 3D models of the Crystal Palace dinosaurs played in the context of Victorian attitudes towards science. In his words, the 'Crystal Palace exhibits can... be understood as the apotheosis of a short-lived conjunction between commercial capitalism and rational education in the early 1850s', at a time, he reminds us, 'when the very notion of the spectacle was under construction.' (Secord 2004, p.139) 


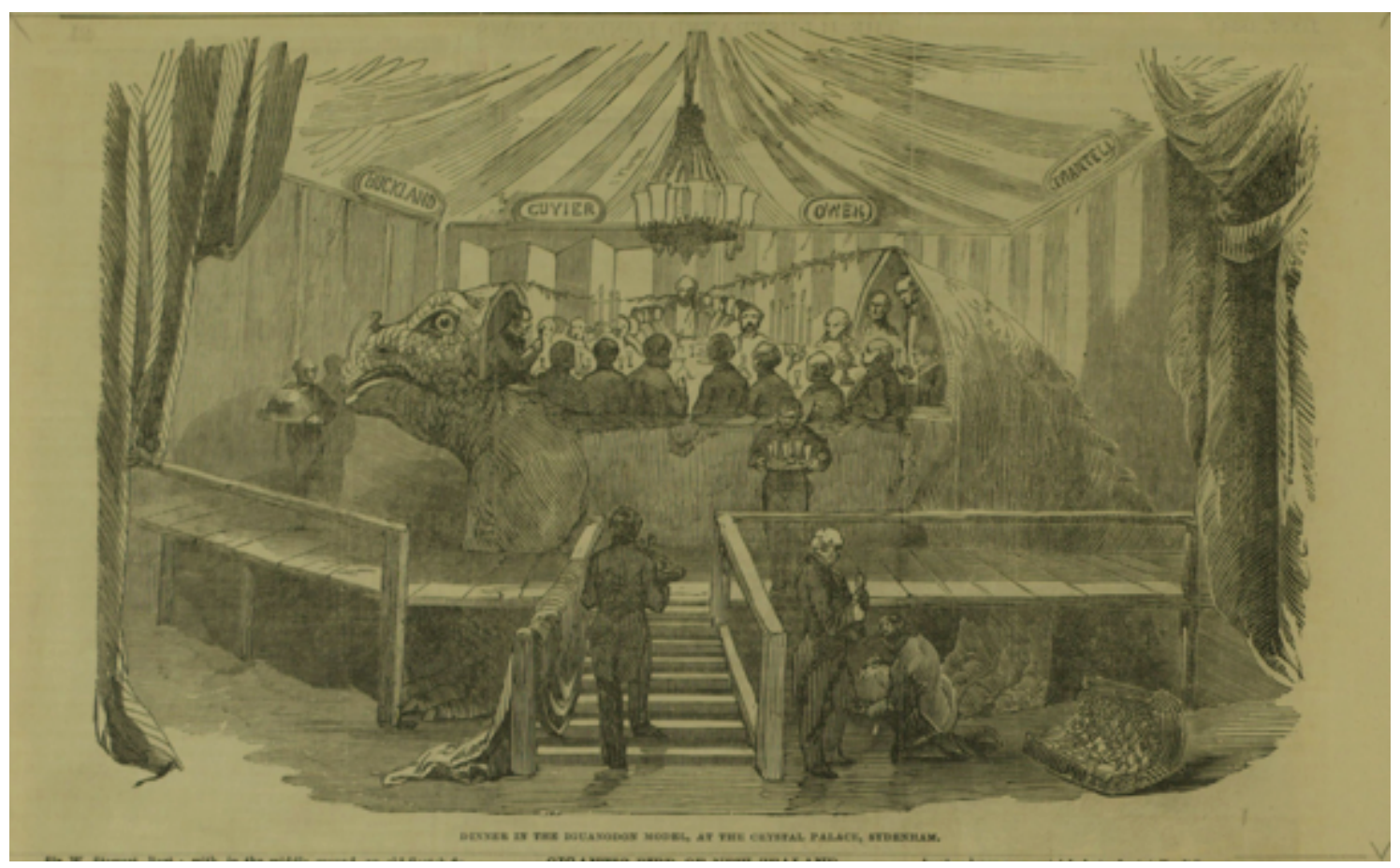

Figure 1. Dinner in the Iguanodon Model, at the Crystal Palace, Sydenham. Illustrated London News, 7 Jan. 1854, p. 22

The Crystal Palace dinosaurs were a remarkable public experiment in visual education. They offer a vantage point from which to reassess what Soraya de Chadarevian and Nick Hopwood have described as the 'dimensions of modelling' in science (Hopwood and Chadarevian 2004). Such objects open-up scientific analysis and understanding to 'the advantages of engagement in three dimensions.' (Hopwood and Chadarevian 2004, p.10) They invite a kinetic, material and wholesale bodily engagement with 'knowledge' that places the dynamics of science in a novel educational and pedagogical terrain. Importantly, three-dimensional models also invite questions about their own internal making, and thus about their relationship to representational techniques such as drawings, photographing, cataloguing, indexing or writing.

This essay offers an account of a present-day experiment in dimensioning 'free' and 'public' knowledge. In fact, the object we shall be talking about has also been dubbed a 'Dinosaur'. 


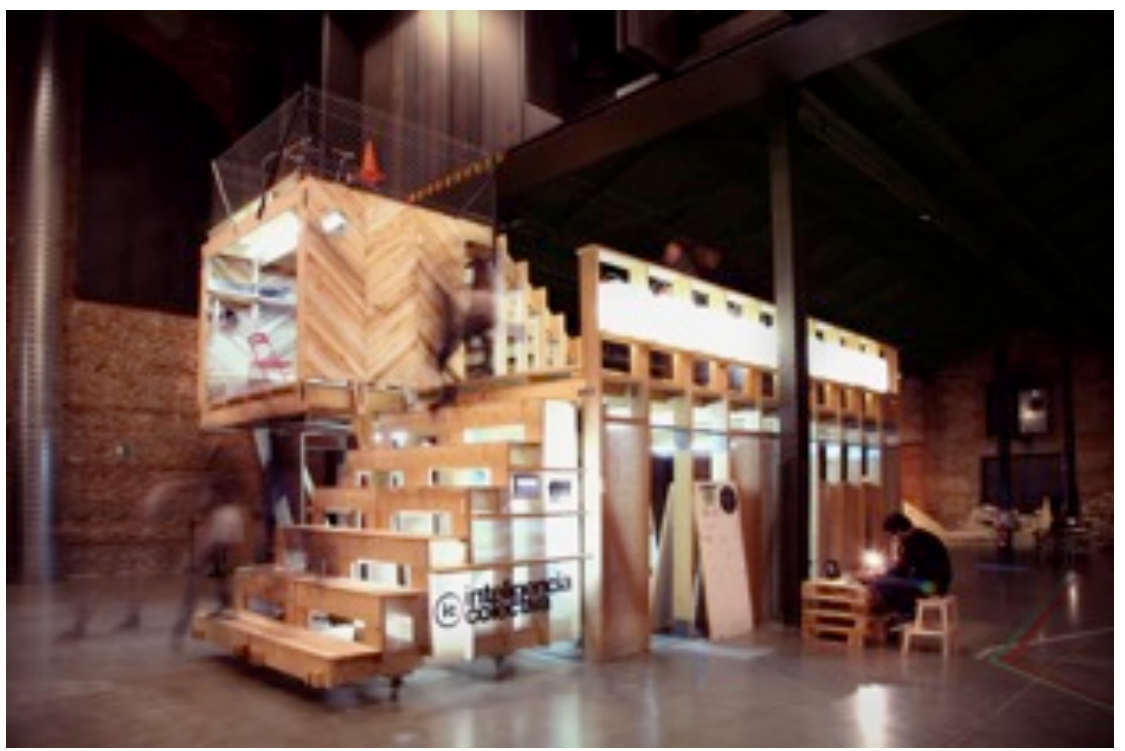

Figure 2. The Offfficina (a.k.a. the Dinosaur). Photograph by Zoohaus

Not unlike the Crystal Palace antediluvian monsters, the material corpus of this dinosaur may also be understood as signalling a series of transformations in the relations between the nature of spectacle and the arts, pedagogy and education, and shifting proprietary formations in the age of networked capitalism. Our focus here, however, is on the 'dimensionality' of the dinosaur as a knowledge-artefact. We want to bring attention to how the dimensional properties of a techno-scientific object, and in particular its interior design, affects its very epistemic status. Ours is a story about the interior design of epistemology.

The story of our Dinosaur is a story about the problems faced by a group of young Spanish architects when trying to build a physical archive for open-source architectural and construction techniques that would fare itself as an object of free culture. It is a story about how an exercise in collecting grassroots, do-it-yourself and autoconstruction architectural and engineering designs and techniques from all over the world, turned over time into a problem in the architectural management of such a collection and, further still, into the challenge of imagining the kind of social collective that would faithfully mirror the 'free' knowledge epitomised by the various constructive techniques. Thus, as time passed, questions about the nature and descriptiveness of data developed into questions about its structure and internal architectonics, only to engender further questions about the interior design of an epistemology (about free knowledge). The essay describes thus the history of the specific design challenges that the architects encountered in coming to terms with the question, 'What kind of architectural object is 
free knowledge?', or as they themselves like to put it, 'What would a prototype of opensource architecture look like?'.

In a recent article Matt Ratto has described an experimental pedagogy that he calls 'critical making' (Ratto 2011). Critical making builds on the tradition of constructionist approaches in critical design (Dunne 2008) and social studies of science (Knorr-Cetina 1999), but unlike these it focuses on the pedagogical importance of developing 'shared construction itself as an activity and a site for enhancing and extending conceptual understandings of critical sociotechnical issues', rather than the making of functional or 'evocative objects' (Ratto 2011, pp.254, 253). Thus, in a critical making project the material construction of an object becomes a means for conceptual exploration. The object thus made is not an outcome or reflection of prior design assumptions and expectations. Nor is it valued for its capacity to work critically as a piece of design. Rather, critical making double backs on the design process to interrogate the epistemic affordances of its own material construction.

The rest of this essay may be read in the critical and exploratory mode suggested by Ratto: as a conceptual and material exploration of what kind of object 'free knowledge' might be. Thus, we first describe the vicissitudes undergone in the design and making of the Dinosaur. As it happens, the Dinosaur has its origins in a pedagogical practice that echoes Ratto's proposal. Back in 2007 the architects developed an interest in grassroots 'architectural intelligences' for exploring how to reimagine the pedagogy of architectural workshops. The project took shape there as an educational challenge, and it was in working out the material, archival, spatial and technical aspects of its pedagogy that architects first ran into the developmental, proprietary and collaborative affordances of open-source knowledge. From there on, the construction of the Dinosaur became an experimental and somewhat erratic encounter with and negotiation around the material, architectural and epistemic constraints animating conceptions of free knowledge as a three-dimensional object. We chart here the Dinosaur's various material and epistemic transformation as it struggled at remaining faithful - and in so doing, reinventing - an architectural conception of free knowledge. The later stages of our ethnographic account of the Dinosaur's travails explore in some detail its ultimate reconfiguration as, in the words of its designers, an 'ambient-machine' and 'eventful infrastructure'.

In the final part of the essay we use the Dinosaur's ethnography to ask some questions about the epistemic architecture of so-called free and open-source forms of 
knowledge. We want to stress the words 'ethnography' and 'architecture' here. We do not so much want to use the Dinosaur case to produce critical analysis about a design tradition or practice, or to use its ethnographic details to illuminate or interpellate aspects of a social theoretical tradition (say, critical design studies, actor-network theory, social studies of science and technology), as to try to let its ethnographic sources transpire their own theoretical purchase. Said somewhat prosaically, our form of analysis is less about 'stepping outside' the material to produce fresh critical lessons, than 'stepping into' and open up the ethnography to have its theoretical affordances, if any, speak for themselves (on ethnographic theory, see da Col and Graeber 2011).

The point about ethnographic theory takes us directly to the question about the internal architectonics of theory. As we shall see, our key ethnographic insight revolves precisely around the architecture of knowing practices: the scalar, dimensional, material, diagrammatic, infrastructural, interventionist and atmospheric properties of architecture. It is by placing these properties centre stage, then, that the essay finally hopes to bring to attention the role that atmospherics, physics and aesthetics ambience, infrastructure and interior design - play in holding forms of (free) knowing together.

\section{Intelligences recollected}

Set up in the early 2000s, the multidisciplinary platform Zoohaus functions as an umbrella operation for a variety of urban grassroots and guerrilla architectural and artistic collectives in Spain. Outside the mainstream architectural studio-world as is conventionally understood, the various individuals and collectives that enrol at different times in Zoohaus projects share a concern for participatory urbanism, sustainable development, recycling, open-source technologies and Situationist-inspired urban interventions, such as employing dérives in their workshops for exploring a neighbourhood's surroundings. Over this time Zoohaus has therefore provided a common-pool resource for young architects and urban activists to share experiences, tools and projects of a kind rarely if ever talked about in architectural faculties or professional architectural firms in Spain.

The story of the Dinosaur sees the light as a Zoohaus project back in 2007. A group of people launched then a project to document what they referred to as 'architectural and constructive peculiarities' found in their travels around Spain. They set up a website which thence functioned as a repository of visual (photographs, videos, diagrammatic 
sketches) descriptions of do-it-yourself, retrofitted, community-driven architectural designs and adaptations. They called the project 'Collective Intelligences' (Inteligencias Colectivas, hereafter IC), for it is to the anonymous, collaborative and do-it-yourself nature of the objects and devices that they found - and keep on documenting to this day - that their attention was drawn to. ${ }^{1}$

Although IC was originally conceived as a visual repository, its first developments were made as an educational tool. In 2009 Zoohaus obtained funding from the Spanish National Agency for International Development (AECID) to carry out a series of workshops on 'grassroots construction techniques' at various design and architectural faculties in Latin America. Throughout 2010 members of Zoohaus travelled the continent teaching students in Lima, Bogotá, Santiago or Buenos Aires, amongst other locations, how to identify and document local do-it-yourself constructive techniques.

In preparation for the workshops, Zoohaus developed a four-step methodology for documenting and describing such techniques. The steps were named, respectively: 'catalogue', 'upgrade', 'prototyping' and 'human network'. At the time of their Latin American tour, the pedagogical programme designed by Zoohaus focused solely on cataloguing and prototyping 'intelligences'. In their words:

We felt there was an expectation from our part to "build" things. This is what we are after all: we're architects, we are in the business of construction. So it was important to have the students build a physical thing in the workshops. We taught them how to catalogue an intelligence and then how to use that description to reassemble it into a new object.

Step by step, the methodological itinerary was designed to work as follows:

The first step is that of cataloguing an intelligence. Attendants to a workshop are prompted to wander around their urban surroundings on the hunt for do-it-yourself, retrofitted or community-driven architectural designs. If they find an intelligence they deem worthy of recording, they are told to document it down to its finest detail, by taking photographs, making drawings, sometimes video-recording the workings of the device in question. These various files are all later uploaded to the IC website. The work of 'cataloguing' involves therefore documenting, indexing and archiving whatever intelligences are found. 


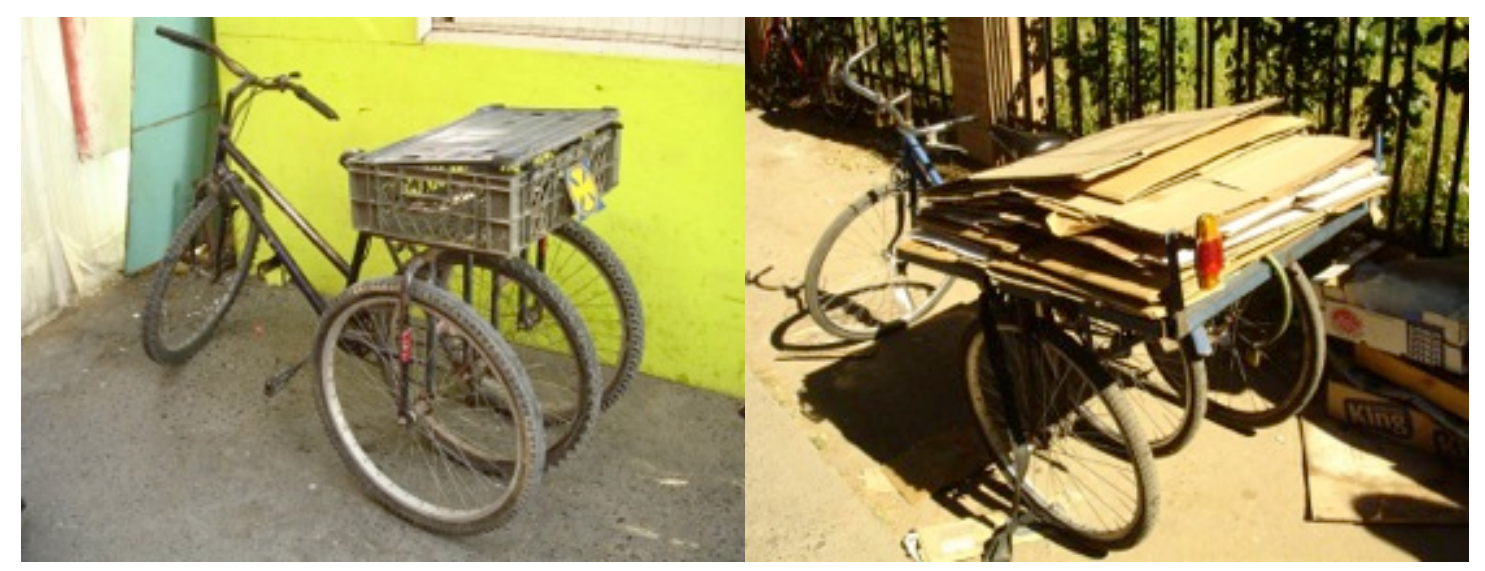

Figure 3. Catalogue of a 'Tetracyle'. Photographs by Zoohaus

The second step involves 'upgrading' such intelligences, although as noted, this has not always been part of the educational workshops. Upgrading an intelligence involves breaking it down into its constituent parts and documenting, step by step, its technical re-assemblage. It is a complex, arduous task, which requires skills in technical drawing, 3D design, often expertise with Autocad architectural projections. The aim of an upgrade is to specify and explain the internal functioning of any device in order to make it replicable.

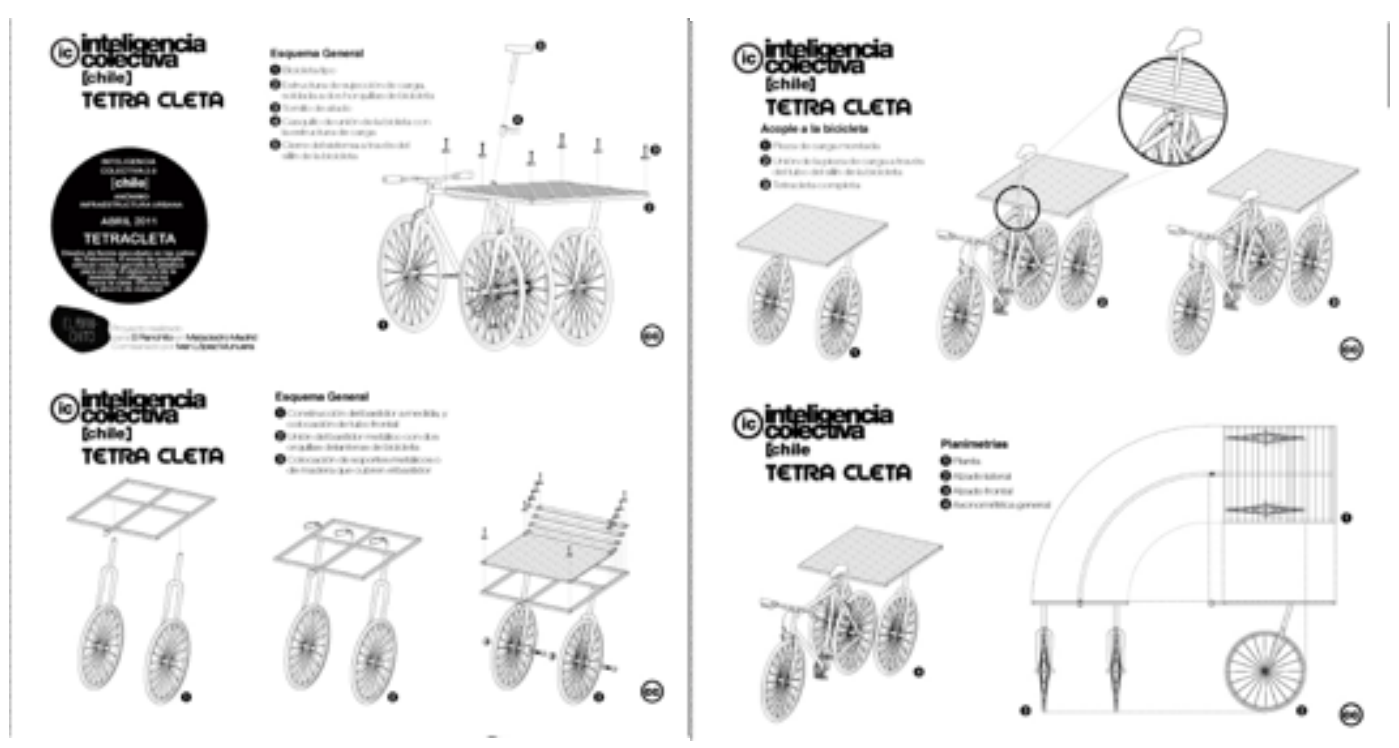

Figure 4. Upgrade of a 'Tetracyle'. Technical drawings by Zoohaus.

The work of upgrading an intelligence echoes in this respect the technical descriptions entailed in patent specification. By drawing things together, the upgrade objectifies the 
intelligence as a representational - and potentially political - form (Biagioli 2011). The specification solidifies an artefact that was up to that point environmentally malleable and distributed. Unlike patent specifications, however, upgrades remain open-ended processes. There are no standards or protocols guiding how an upgrade ought to be carried out, and indeed Zoohaus is still to this day engaged in an inventive exploration of the very methodologies to be employed in the documentary production of an upgrade. As the architects put it, 'we are still learning what an upgrade may actually entail'. $^{2}$

There are a number of reasons that explain the difficulties encountered in defining the methodology of upgrading. For a start, most intelligences are singular constructions. They are unique adaptations to a local environment. Even if materials, technologies or design compositions can be replicated, it is unlikely that an upgrade can describe how and why an intelligence provided a constructive solution where and how it did so. Sometimes, also, the original development of an upgrade cannot be documented: for example, because its makers are not around; or because there are various problems to which the object is used as a solution and nobody quite knows what circumstances first prompted its manufacturing. Thus, although an artefact can of course be analytically deconstructed, it may not always be possible to re-construct its contextual application.

The third step in the methodology entails the actual 'prototyping' or construction of an intelligence. This is a hands-on activity where students are required to make a physical object. Such objects, however, must offer a constructive solution for a context other than the intelligence's original context of invention. Students are therefore here encouraged to, in the architects' idiom, 'evolutionize' the intelligences, by which it is meant that they must look for ways to adapt the designs outside their original remit and location. They must disembed the object from its original setting and stretch its design to adaptive solutions elsewhere. The challenge, in the architects' own words, is to find 'an enunciation that affords the prototype a meaningful and productive application.' The crucial words here are 'enunciation' and 'evolution': they both point to a vision where the prototype is as much a contextual as a technical development. The challenge for the students is therefore to design or enunciate a context wherein the prototype grows and evolutionizes.

The fourth step involves mapping the social relations of an intelligence. This is the 'human network': the people who were involved in the original design of the intelligence, or who have become custodians or transmitters of such an intelligence. 
They are the people who know how to make such intelligences, how they work, where to source them from, etc. The task of describing a human network is implicit, of course, in the operation of prototyping, insofar as a prototype is conceived as an intelligence that has been 'evolutionized' out from its original context of invention. Knowledge of this context is therefore a requisite for the proper development of the prototype. Ideally, such knowledge would take an ethnographic form. Descriptions of human networks, however, vary considerably. For some projects, the human network amounts to little more than a naming of the people who participated in the making of the original object and its prototypical extension. Other projects make use of video-interviews; in yet other cases, an attempt is made to contextualize the territory, context or circumstances that prompted the creation of the intelligence. Most human networks, however, come to life as collections of digital media: video, audio or image files.

Altogether, then, there are no standards as to how to catalogue, upgrade, prototype or map a human network. Different intelligences have to this day prompted different recollections. What perhaps best describes the state of the IC platform towards the end of 2010 was its redefinition from its original status as a project that aimed to document and map grassroots architectural intelligences to a collective exercise in networking and distributing social relations. The IC project thus epitomised at this stage the kind of reorganisation in the nature of the experimental that Latour has described as a transition from an enterprise in 'data collection' to a 'collective enterprise' (Latour 2011).

\section{Self-maintenance}

Upon returning from Latin America Zoohaus was invited to an artistic residence at El Ranchito, a curatorial project in Madrid's leading contemporary arts centre, Matadero. The invitation expressed the art centre's interest in exploring some of the wider implications of the IC project. The interest was a part of a nascent and vibrant movement that was taking root in the city around questions of 'free culture' and which had gained momentum through the activities of a couple of self-organized squatted centres and hackerlabs, and the remarkable concession by the Ministry of Culture on February 2010 of a permit to 'occupy' an emblematic old tobacco factory in downtown Madrid to a group of experimental artists, educators and squatters. The commission by El Ranchito followed on the steps of this experimental moment. 'What would a "free knowledge bank" look like', asked the commissioning invitation, 'if it were to be designed as an architectural object? Could one build a meta-prototype that fed on all 
IC's projects to date, and that would become in turn a space from where to promote the prototyping of further intelligences?'

Zoohaus took the art centre's challenge to heart and developed a proposal to extend and apply the IC programme to Matadero's local neighbourhood, Arganzuela. They proposed to construct an office space that would become an archival and intellectual platform for the development of a local IC programme within the neighbourhood. The office, the proposal suggested, would host a physical archive containing all the project's intelligences, as well as a workshop space from where to launch a survey of Arganzuela's own local intelligences. The office proposal was named OTICAM: IC's temporal office in Arganzuela, Matadero (Oficina Temporal Inteligencias Colectivas Arganzuela-Matadero).

The proposal that Zoohaus presented to Matadero spoke of IC as an object 'without an owner, a tool in the service of everyone' (Zoohaus 2010, p.3). The text further described the office as a 'physical an eventful materiality', by which it was meant that the office space would 'host open events that will function both to recruit and enlist new intelligence-seekers', as well as 'explain and publicize' the project's general programme (Zoohaus 2010, p.3). The office was thus conceived to work as an archive, workshop and eventful space. Importantly, also, the project's identity was deliberately kept loose and ambiguous. Zoohaus insists that this is the work of an open platform. 'We want to give voice to the authors of the intelligences, and in so doing dilute the platform's own authorial identity. The platform should be thought-of as an instrument rather than a model or project.' IC is at once an 'infrastructure' and a 'social network' (Zoohaus 2010, p.6). In its most succinct formulation, the office is imagined as a 'prototype of and for collective intelligences' (Zoohaus 2010, p.8).

In the days prior to the approval of the project by Matadero, Zoohaus sounded a second idea with one of the centre's curators: to develop an identity as Matadero's 'maintenance architects'. The idea was to apply a variety of intelligences to the art centre's very own infrastructure: to expose the repair work that goes into holding 'art' together as an epistemic and material object. The proposal, however, was quickly dropped upon concession of the project on July 2011, and Zoohaus turned their attention instead to the building of OTICAM.

The project was set in motion erratically and without much direction. Zoohaus started using the space provided by Matadero for all kinds of business, related or not to the IC project. Zoohaus had no office of its own so the workspace provided by 
Matadero was used at leisure by the architects for all kinds of work. 'Visitors to Matadero', we were told in conversation, 'dropped by our working space and were bedazzled at what we were doing there. We ourselves were not much better at explaining our own presence there.' For a start, the architects struggled with the notion of an 'archive':

We had this vague idea about spatializing onto a 3D object the affordances of a digital archive. We also wanted the archive to work as a sort of 'shelf for relics': a museum of intelligences, where people could touch and play with real artefacts. And of course we also wanted the archive to be a meeting place: a space itself enabling of new intelligences. Last, it was our hope that whatever we ended-up constructing would stay in Matadero. We wanted to build something that would remain in the arts centre past its exhibition date.
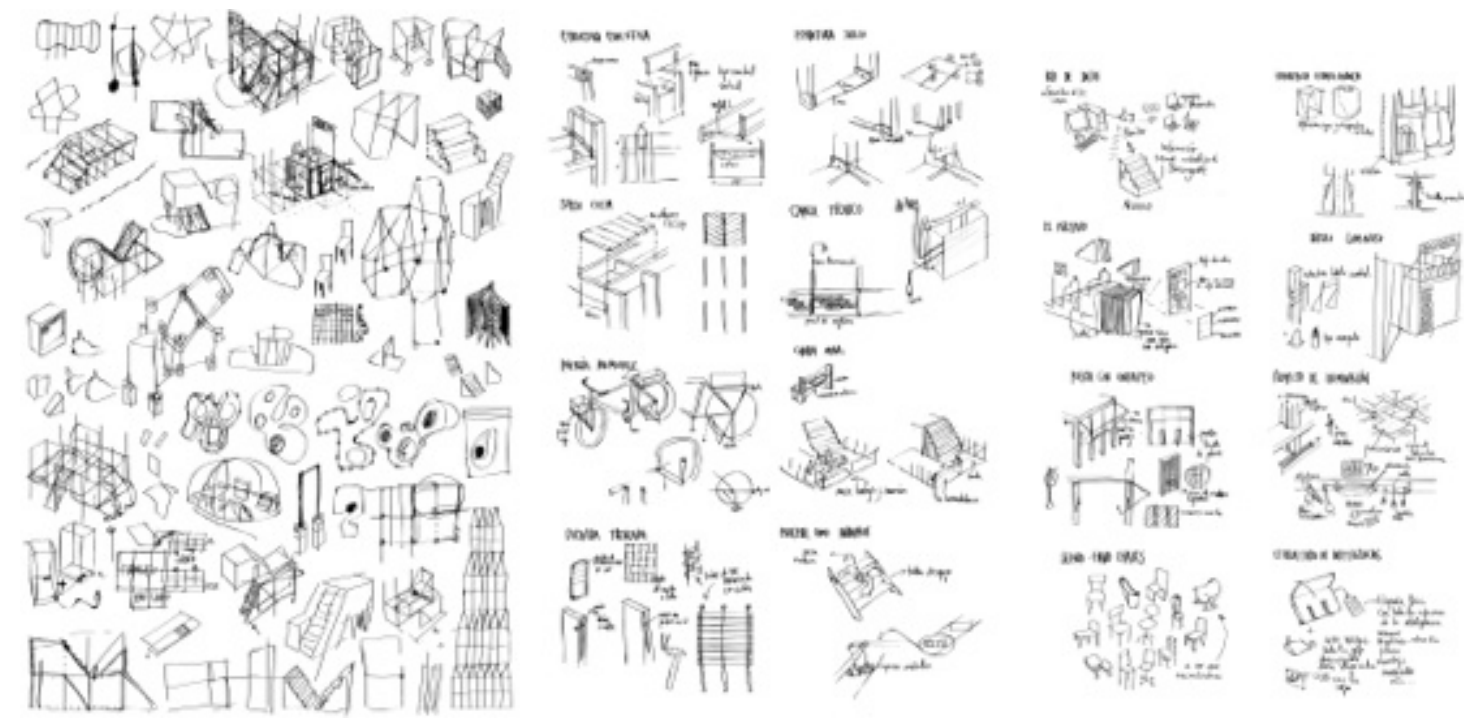

Figure 5. Sketches of the various 'intelligences' that should assemble together in the making of the Offfficina. Drawings by Zoohaus.

Meeting after meeting the Zoohaus team deliberated how to build such an archive. Although their objectives were unstable and shifting, Matadero's own infrastructure soon beame an obstacle itself:

We certainly hadn't much idea as to where we were going. But it didn't help that our own workspace in Matadero wasn't properly equipped for the task at hand. 
There were hardly any electricity sockets were to plug our laptops; sometimes, at a meeting, someone wanted to show the rest of the team a video, but we had neither a projector nor a screen where to watch them. We even had no archival space of our own, no storage proper. So it soon became obvious that we really had to build an archive. The archive wasn't going to be simply a content-holder for the IC project. It was first and foremost an infrastructure. Suddenly, therefore, the archive grew.

Zoohaus had hitherto imagined OTICAM as an intellectual platform: a free knowledge bank that acted as both a repository of local intelligences and an atelier for building up new communities of intelligence-seekers. The project soon changed direction, however. At every meeting the architects ended-up talking about the infrastructures that were lacking in Matadero:

Then, one day, we suddenly realised that not one of the other artists-in-residence were working for Matadero. No one was working towards making Matadero a better place. No artistic project had taken Matadero as its own object of intervention. Why not, we thought then, build an office such that it becomes an infrastructural enhancement for Matadero? That would be our prototype: a piece of infrastructure grafted onto Matadero's structural habitus, enabling of its own activities.

The idea of building up the archive as a form of infrastructure came as a revelation. The architects suddenly realised that what mattered in the construction of a 'free knowledge bank' was the construction, not the 'freedom': the design of infrastructural capacities, rather than simply the terms and conditions of access. ${ }^{3}$ Thus, Zoohaus's flippant proposal to become Matadero's 'maintenance architects' returned in the re-imagination of OTICAM as a platform enabling of the arts centre's own curatorial projects. The office become a self-maintenance infrastructure.

\section{Self-instructable}

The new vision for the project opened-up a whole new series of challenges: 
Would it be possible, we asked ourselves, to build the office using the intelligences IC had collected the world over? Could we take an intelligence found, say, in Palomino (Colombia) and retrofit it with one found somewhere else? That may sound rather banal to you, but it addressed a crucial challenge for us, namely, can architecture be open-sourced? Can an architectural intelligence be disembedded from its local context and material circumstances, and made to travel elsewhere?

The question of retrofitting assumed a pivoting role in the imagination of the office as a structural assemblage. For Zoohaus, the open-source nature of the building required not only the use of Creative Commons licenses, but more importantly the design of an constructive system capable of self-aggrandizement or self-miniaturization. 'We had to build an object capable of accommodating future needs. Thus, whose sources were open (open-source), but also whose own internal resourcefulness remained open. That was the point of the turn towards infrastructure: designing and building an object capable of transforming itself into a resource for others.' The inspiration here came from the autoconstruction techniques that have become a trademark in the fringes of Latin American urbanization (Holston 1991). The office was thus imagined as a re-compositional object: made-up with intelligences that can substitute for each other, or even enhance and transform each other; structures that can anticipate future structures. An object whose capabilities were self-instructable.
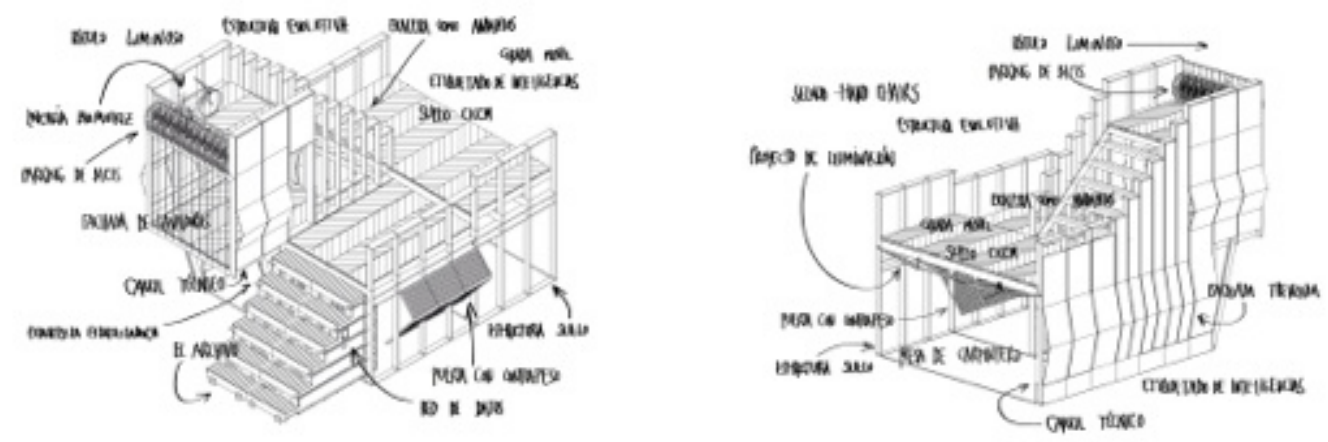

Figure 5. Visions of a modular and self-instructable Offfficina. Sketches by Zoohaus.

The construction of the office advanced at good pace over the following months. The building's design changed a number of times, such as when Matadero offered Zoohaus 
free wood with which to build the structure in exchange for their collaboration dismantling an existing exhibition piece. The wood allowed Zoohaus to develop a more ambitious plan for the building, but such transformations were in accord with their newfound programme for a self-instructable construction. This newfound identity also prompted a chance of name for the project. OTICAM was now renamed Offfficina, in homage to the image-bookmarking and web-based curatorial project, FFFFound!

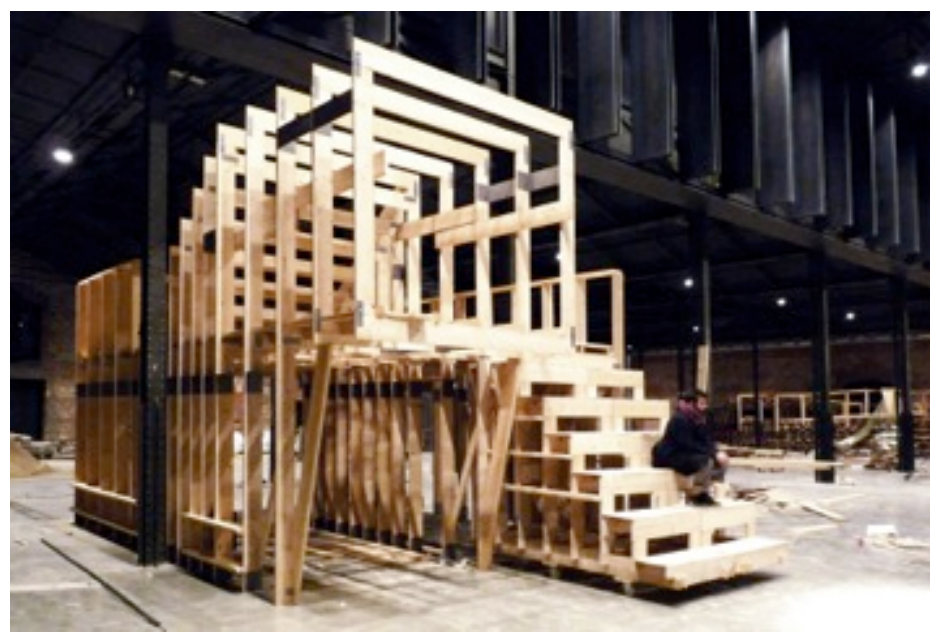

Figure 5. The making of the Offfficina. Photograph by Zoohaus.

The peculiarity of the installation that Zoohaus was building for Matadero was first brought to the attention of the art centre's curators and management staff a few weeks prior to the exhibition's opening. All artists were then notified of the need to start moving their pieces from the workshop areas to their final residence in the exhibition hall. The news came as a shock to Zoohaus. The office built by the architects had been designed and dimensioned to their working area. It had never occurred to them that the structure would have to inhabit a space other than its own constructive space: 'The thing is that we were building our own space. This distinction between a workshop space and an exhibition space was pointless to us. Our exhibit was our workspace.'

In the months to come this vision of a self-built, autonomous space took a life of its own and in important ways contributed towards reconfiguring the Offfficina's identity from collaborative intelligence to infrastructural event.

A turning point in such re-conception was marked by Matadero's invitation to all El Ranchito artists to organize a series of workshops that would contribute towards publicizing their artwork. Without giving it too much thought Zoohaus decided to organize the workshops at the Offfficina. They sent out invitations and scheduled the 
workshops appropriately. It is only later that they realised that not being under the obligation to ask Matadero's administrators to book a workshop space on their behalf, or ask permission to use certain infrastructural equipment, had suddenly turned the Offfficina into its own curatorial project. In their own words:

It was this sudden realisation: 'Shit, we have our own curatorial space here'. A place of our own, which is grafted onto Matadero's infrastructure, which parasites on Matadero, but that we manage. A space with no owners. In fact, it becomes this tiny bit of Matadero that suddenly 'anyone' can manage, for anyone can join IC. So from one day to the next, you have this public space, run and administered by the state, and yet with a loophole in it, that allows anyone to manage it.

From that moment on the Offfficina became a very different kind of object. Zoohaus opened-up the platform to fellow artists and collectives, who started using it for a variety of purposes: book launches, academic seminars, parties, artisanal workshops; the Offfficina became an eventful infrastructure.

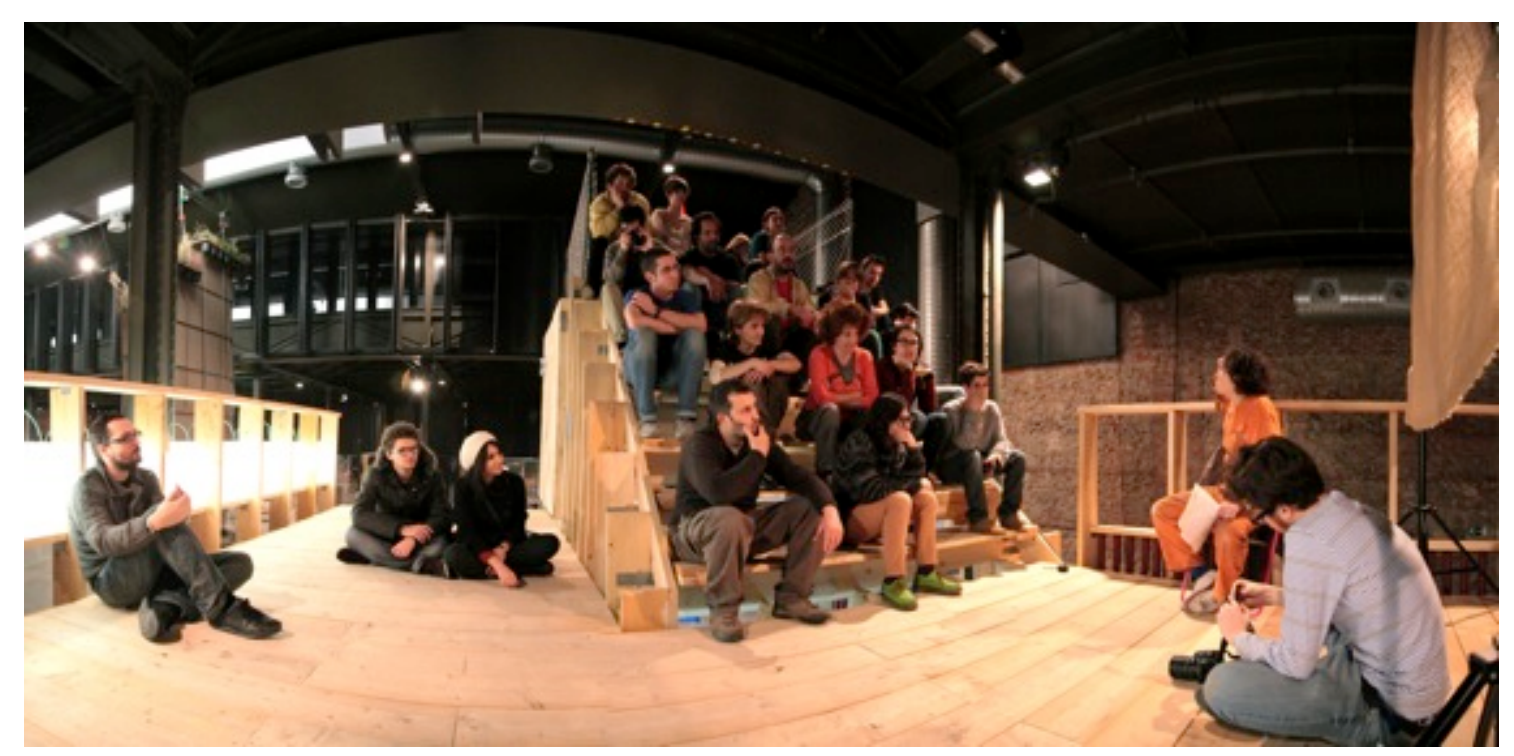

Figure 6. Seminar at the Offfficina. Photograph by Zoohaus.

There are a number of restrictions, however, on what the Offfficina can be used for. The Offfficina is a free culture infrastructure, so all events hosted at the Offfficina are free, as in gratis, but also free as in promoting free knowledge. Thus, if it is viable 
technically and organisationally, events ought to be streamed live over the Internet, and all related documentation and audio-visual materials likewise made available under Creative Commons licenses. Some members of Zoohaus speak of 'a natural evolution of the philosophy of openness that leads to the production of 'situations' or 'ambiences'.' Thus, for instance, at a workshop organized for teaching how to built doit-yourself rocking chairs participants were asked to source their designs from the needs of Matadero's back-office and maintenance personnel. The chairs, once built, were offered to the arts centre's staff in appreciation for their on-going support, and have become today a recognisable item of the centre's furniture-scape.
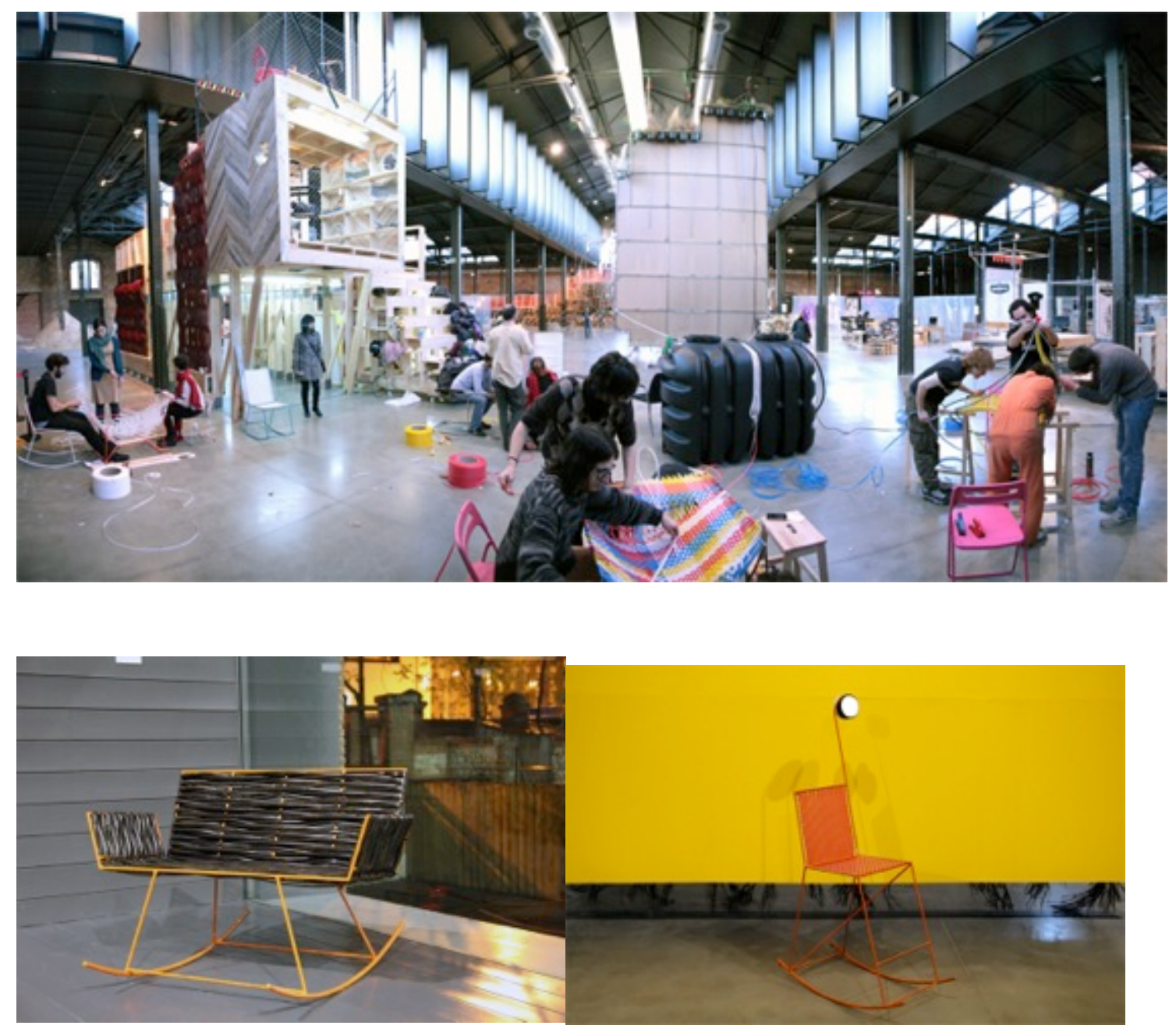

Figure 7. Workshop on do-it-yourself rocking chairs (Mecedorama) and examples of two chairs in use as Matadero's furniture.

\section{Atmospheric infrastructure}


As noted in the introduction, the history of the Offfficina's design and construction echoes aspects of the 'critical making' experimental projects outlined by Ratto. For a start, the original workshop pedagogy that Zoohaus developed during their Latin American tour does indeed share many-a-one characteristics with the critical making approach. Thus, the task of 'enunciating' and 'evolutionizing' intelligences into exportable prototypes opened-up, as the architects themselves pointed out, the epistemic tensions and potentialities within every device. The making of prototypes enabled a critical engagement with the tasks of description (upgrading), contextual understanding (human network) and techno-material development (from prototype to infrastructure). Moreover, the very development of the IC project from digital repository to archive, then office, and finally eventful infrastructure, signals to this internal capacity of the project to take its own infrastructural (self-maintenance and self-instructable) qualities as a source of critical and conceptual development.

In this sense, it is perhaps worth distinguishing between a 'constructionist' and what we shall call, for lack of a better term, an 'infrastructural' approach to critical making. Constructionist approaches tend to focus on the semiotics of material exploration and play as sources of pedagogical insight and reflection. It is the kinetic and bodily engagement with matter that crafts, modulates and nurtures the epistemic buildingblocks for critical thought.

We would like to stress here, however, not the constructionist qualities of the Offfficina but its infrastructural ones: the features we have called 'self-maintenance' and 'self-instructability'. These are qualities, we want to suggest, that emulate on a physical plane what Chris Kelty has described as the 'recursiveness' of free software: its simultaneous development as an infrastructural and social project; as code and as collective (Kelty 2008, see also Corsín Jiménez's Introduction in this volume). Every bit of code developed, every piece of wood added to the Offfficina, signals both an infrastructural extension and a social capacity.

There is, however, a third dimension to the recursive work of the Offfficina that distinguishes its work as a critical infrastructure. We refer to the role of atmospherics, of ambience, which was first brought to our attention during the fabrication of the rocking chairs.

That the rocking chairs workshop enabled the Offfficina to intervene in Matadero's ambience through the shaping and moulding of its interior design is hardly worthy of commentary. The chairs quite literally re-decorated the art centre's space. Far more 
significant, however, is the role that the Offfficina played over the coming months in the reconfiguration of the role of architecture as both cultural and political praxis in Madrid. Throughout 2012 the platform became a meeting point for 'Arquitecturas Colectivas', a network of young architectural collectives aimed at showcasing the work of emerging grassroots and guerrilla architects hitherto ostracised by the mainstream world of 'studio' architecture. Thus, the Offfficina became a place for these architects and fellow interlocutors - artists, digital activists, cultural agents - to hang out. Its infrastructure opened-up a space where an emergent conversation about peer-to-peer urbanism, open-source architecture or networked collaboration took root. Furthermore, it enabled certain events, such as seminars, book launches or workshops, to acquire, as the architects themselves often put it, a 'situationist' character. Not unlike what McKenzie Wark has observed apropos de Situationists' visions for an urban world of pure possibility, the Offfficina engineered the type of 'atmosphere [that] gave [the Situationists] intimitations of the future powers of an architecture it would be necessary to create as the ambiance for less mediocre games.' (Wark 2008, p.7) Over time, the Offfficina's open-source architecture became the place to talk about open-source architecture in Madrid. We may say that the Offfficina's infrastructure quite literally theatricalized - provided the dramaturgical and decorative context - for open-source architecture to take centre stage. As a gigantic piece of interior decoration, the Offfficina supplied the atmospherics for making open-source architecturally visible in the city.

Thus, to the importance of self-maintenance and self-instructability for the work of recursive infrastructures, we would like to add too that of the criticality of interior design. The atmospherics enabled by the Offfficina's infrastructural spatiality echoes in this regard the argument made by Javier Lezaun and Nerea Calvillo in this volume about the relationship between the interior design of Kurt Lewin's experimental layouts and his theories of political and 'social climates'. In their account, Lezaun and Calvillo show the extent to which Lewin's theory was 'artefactualized' and embalmed in the dramaturgical ambience lent to the experimental design. Although they do not cite the work of Gernot Böhme, their description of the material layout of a 'climate' echoes Böhme's important writings a propos the way in which 'atmospheres' are bodied forth and 'created by things, persons or their constellations.' (Böhme 1993, p.122) Böhme's essay, which is a contribution to a new aesthetics (understood as a general theory of perception), makes an original argument for thinking of atmospheres as a crucial piece 
in any ontology's furniture. For Böhme, the atmospheric is irradiated as the 'ecstasies of the thing[s]' that make up a spatial and infrastructural environment (Böhme 1993, p.121). 'The primary “object” of perception', he writes, 'is atmospheres.' (Böhme 1993, p.125) The atmospheric, then, is a quality of the arrangement and choreography of objects and things in an interior design.

\section{Conclusion: 3D social relations}

The curatorial project (El Ranchito) that hosted the Offfficina was scheduled to close in April 2012. It soon became obvious to both Matadero's administrators and Zoohaus that the scale of the project would eventually pose a serious curatorial dilemma to the art centre. The Offfficina's infrastructural intervention was unlike anything El Ranchito had commissioned. It was not so much the size of the installation, for the art centre has housed considerably larger exhibits and pieces throughout its history. Rather, the Offfficina literally opened-up an infrastructural dimension within the art centre. It brought to attention some infrastructural and technological deficiencies of the centre, but perhaps most importantly, it did so by pointing to an alternative conception of infrastructure as a form of collaborative intelligence and ambience-making.

For Zoohaus, the realisation that the Offfficina entailed an infrastructural enhancement of Matadero meant that it was imperative to get the art centre to keep the installation, but most importantly, to make sure it remained open and operative as an infrastructural centre. It is at that point that Zoohaus launched an imaginative campaign to 'save the Dinosaur', as the Offfficina was affectively renamed. The architects printed t-shirts with the Dinosaur's image, which were handed out for free amongst Matadero's staff, and embarked on a social media campaign to 'mobilize empathy for the Dinosaur's cause', as they put it. 


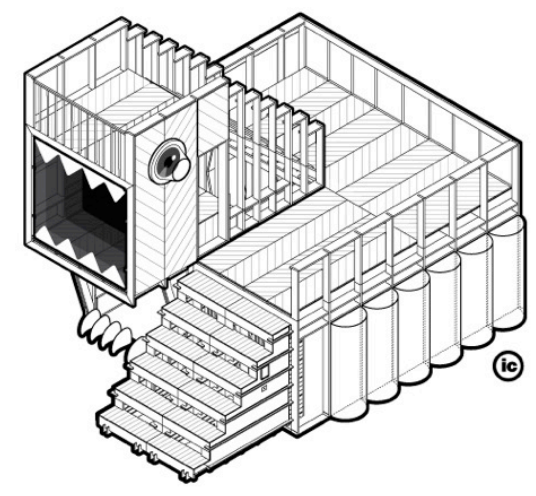

\section{\#savethedinosaur}

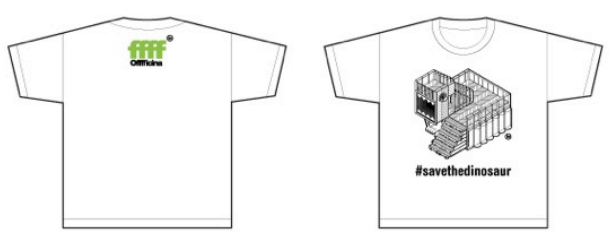

Figure 8. Iconography for the Save the Dinosaur campaign. Image by Zoohaus.

The choice of imagery is worth a comment. The idea of investing the infrastructure with a 'monstrous' aesthetic had long circulated within Zoohaus:

We were of course inspired by the work of Adolf Loos, who used to 'animalise' his architecture. But actually the Dinosaur was always more of a pet for us: a little house-pet. We thought it was important to invest the installation with that dual aesthetics: the warmth of the hearth, of a domestic ambient; a little house that welcomes all and everyone. A place that is familiar and makes you feel at home. But also the cuteness of the house pet: something you want to play with, as well as an object of desire.

There is more to the antediluvian 'monster' than its affective qualities, however. At another time, members of Zoohaus noted that the construction of the Offfficina as a superposition and ensemble of different intelligences could be thought-of as 'the bringing to life of a kind of Frankenstein.' The formula echoes a remark by the makers of the Crystal Palace dinosaurs, a propos the construction of such 3-D objects as similarly "Frankensteinic", which as James Secord observes expresses their concern for the way the models 'posed an intricate combination of aesthetic, scientific, and practical problems.' (Secord 2004, p.148) For the scale of the Crystal Palace monsters 
was indeed of its time: a historical period that had a taste for 'theatrical spectacle and extravagant stage sets' (Secord 2004, p.143), and that in this context placed a premium on knowledge conveyed through the senses: a philosophy of visual education where "the size, life-like character, and three-dimensionality of the restorations would appear as a revelation.' (Secord 2004, p.141)

If the Crystal Palace dinosaurs reproduced therefore a period discourse about the pedagogical values of sensory and material dimensionality, we may think of the Dinosaur as setting in motion instead a discourse about the dimensional value of education and knowledge. Not knowledge as something to be apprehended through size, but the realisation that all knowledge comes in 'sizes'. Marilyn Strathern once wrote of the Melanesian model of personhood that 'Persons act as though they have a fractal dimensionality: however much they are divided or multiplied, persons and relations remain in proportion to each other, always keep their scale.' (Strathern 1993, p.49) We want to suggest here that the inhabitants of the Dinosaur act analogously as though they have an infrastructural dimensionality: persons and relations extend their capacities through infrastructural and atmospheric interventions. Said differently, it takes three dimensions (3Ds) to describe the work of social relations. We bring our argument to a close on this note, with a comment on how three-dimensional descriptions of social relationships may be seen to inflect the 'interior design' of knowledge.

In a recent article, Alain Pottage has described the role that scale-models played in the formation of 'invention' as a legal concept in $19^{\text {th }}$ century patent law (Pottage 2011). Such 3D models provided a visual, material and tactile representation of how a machine worked, and in so doing 'machined' themselves a conceptual and performative imago of how and what 'invention' was supposed to be about. The scale-models assembled, staged and theatricalised the drama of invention in the courtroom as a mechanical function. ${ }^{4}$ They 'did' invention as miniature representations. Pottage's argument echoes here Mario Biagioli's account of the role of the written patent specification in the 'textualization of invention' (Biagioli 2006, p.1160). In both cases, the model and the text work as 'a kind of pre-conceptual condition for the formation and manipulation of legal concepts.' (Pottage 2011, p.627)

We would like to place the story of the Dinosaur in this larger context: to think of the Dinosaur, not as a model, and certainly not as a textual object, but as a prototype - a term employed by Zoohaus itself. We want to cast a light on the architectural sensibilities and materialities through which the making of the Dinosaur suffuses the 
rather vague notions of free culture and knowledge with prototypical and material qualities, even ontological qualities, in Gernot Böme's amplified sense of the term. In particular, we are interested in the atmospherics, physics and aesthetics - the ambience, infrastructure and interior design - through which Zoohaus brought to life the notion of 'collective intelligence' as a material prototype.

As such a prototype, the Offfficina is performed and theatricalised as self-made and self-instructable, an object of maintenance and repair-work. It is therefore a constructionist system, in both its architectural, critical design and sociological meanings: it is dimensional and compositional, an effect of modular and transformative relations. But it is also, as we noted above, an ambient-object, a piece of interior design. The Offfficina deployed its infrastructural capacities to furnish the art centre's interior decoration. More ambitiously, however, the Offfficina may also be seen as attempting to furnish Madrid's architectural scene with a political programme for open-source urbanism. It became the first meuble of the city's open-source furniture-scape, and it did so by putting its self-maintenance and self-instructable capacities to atmospheric effect. The little house pet became an urban ambient machine.

Thus, if scale-models and textual specifications once played a crucial part in assembling a legal repertoire for the figures of invention and patent, it has been our intention in this essay to open a space from where to rethink the role of infrastructure, maintenance and interior design in the formation and formatting of emerging conceptions of free knowledge and free culture.

\section{Acknowledgements}

Our warm thanks to all Zoohaus' contributors to the Inteligencias Colectivas project. Special thanks are due to Manuel Domínguez, Juanito Jones and Manuel Pascual for their recollections and stories about the Dinosaurs' travails.

\section{References}

Biagioli, M. (2006). Patent republic: representing inventions, constructing rights and authors. Social research: an international quarterly, 73(4), pp.1129-1172.

Biagioli, M. (2011). Patent specification and political representation. In M. Biagioli, P. Jaszi, \& M. Woodmansee, eds. Making and unmaking intellectual property: creative production in legal and cultural perspective. Chicago and London: The University of Chicago Press, pp. 25-39.

Böhme, G. (1993). Atmosphere as the Fundamental Concept of a New Aesthetics. 
Thesis Eleven, 36(1), pp.113-126.

Da Col, G. and Graeber, D. (2011). Foreword: The return of ethnographic theory. HAU: Journal of Ethnographic Theory, 1(1), pp.vi-xxxv.

Corsín Jiménez, A. (2008). Introduction: well-being's re-proportioning of social thought. In Culture and well-being: anthropological approaches to freedom and political ethics. London: Pluto Press, pp. 1-32.

Dunne, A. (2008). Hertzian Tales: Electronic Products, Aesthetic Experience, and Critical Design. MIT Press.

Holston, J. (1991). Autoconstruction in Working-Class Brazil. Cultural Anthropology, 6(4), pp.447-465.

Hopwood, N. and Chadarevian, S. de. (2004). Dimensions of modelling. In S. de Chadarevian \& N. Hopwood, eds. Models: The Third Dimension of Science. Stanford, California: Stanford University Press, pp. 1-15.

Kelty, C.M. (2008). Two bits: the cultural significance of free software. Durham and London: Duke University Press.

Knorr-Cetina, K. (1999). Epistemic cultures : how the sciences make knowledge.

Cambridge, Mass.: Harvard University Press.

Latour, B. (2011). From Multiculturalism to Multinaturalism: What Rules of Method for the New Socio-Scientific Experiments? Nature and Culture, 6(1), pp.1-17.

Pottage, A. (2011). Law machines: Scale models, forensic materiality and the making of modern patent law. Social Studies of Science, 41(5), pp.621-643.

Ratto, M. (2011). Critical Making: Conceptual and Material Studies in Technology and Social Life. The Information Society, 27(4), pp.252-260.

Secord, N. (2004). Monsters at the Crystal Palace. In S. de Chadarevian \& N.

Hopwood, eds. Models: The Third Dimension of Science. Stanford, California: Stanford University Press, pp. 138-169.

Sen, A. (1999). Development as freedom. Oxford: Oxford University Press.

Strathern, M. (1993). One-Legged Gender. Visual Anthropology Review, 9(1), pp.4251.

Wark, M. (2008). 50 Years of Recuperation of the Situationist International. New York: Princeton Architectural Press.

Zoohaus. (2010). inteligencia colectiva_[officina OTICAM]. Proyecto desarrollado por Zoohaus para el Ranchito. Matadero Madrid. Comisariado por Iván López Munuera.

\section{Notes}


${ }^{1}$ We follow the project's convention and hereafter refer to each such design or device as an 'intelligence'.

2 An upgrade's designs and specifications are all made available under Creative Commons licenses, a practice that extends to all IC materials at large (documents, photographs, videos, plans, etc.).

${ }^{3}$ A formula reminiscent of Amartya Sen's famous theory of ethics and freedom in terms of the building of capabilities (for example Sen 1999). Sen distinguishes between functionings (achievements) and capabilities (freedom to achieve). Thus, having a wellfunctioning 'free knowledge bank' does not necessarily mean that we also have the capability to make it work to our advantage. For an anthropological exploration of Sen's writings, see Corsín Jiménez (2008).

${ }^{4}$ Incidentally, they did so in Frankensteinic fashion, too. Pottage thus recounts how the materiality of models as the 'basic medium in which inventions were revealed, scrutinized and compared' was described in an 1848 practical treatise as: "“two-thirds of the time the first sight [a patent attorney] gets of an invention is the "monster model"... in all its hideous array of pine sticks and leather, dumped on his office floor"' (Pottage 2011, p.624). 